\title{
Evolution of Drug Delivery Systems for Recurrent Aphthous Stomatitis
}

\author{
Ine Suharyani ${ }^{\text {I,2 }}$ \\ Ahmed Fouad Abdelwahab \\ Mohammed $^{3}$ \\ Muchtaridi Muchtaridi (iD) 4 \\ Nasrul Wathoni (iD) \\ Marline Abdassah' \\ 'Department of Pharmaceutics and \\ Pharmaceutical Technology, Faculty of \\ Pharmacy, Padjadjaran University, \\ Sumedang, Jatinangor, 45363, Indonesia; \\ ${ }^{2}$ School of Pharmacy Muhammadiyah \\ Cirebon, Cirebon, Kedawung, 45153, \\ Indonesia; ${ }^{3}$ Department of \\ Pharmaceutics, Faculty of Pharmacy, \\ Minia University, Minia, 61517, Egypt; \\ ${ }^{4}$ Department of Pharmaceutical Analysis \\ and Medicinal Chemistry, Faculty of \\ Pharmacy, Universitas Padjadjaran, \\ Sumedang, Jatinangor, 45363, Indonesia
}

Correspondence: Nasrul Wathoni; Marline Abdassah

Department of Pharmaceutics and Pharmaceutical Technology, Faculty of Pharmacy, Universitas Padjadjaran, Jln. Raya Bandung-Sumedang Km. 2 I

Jatinangor, Kab., Sumedang, Jatinangor,

45363, Indonesia

Tel +62 22842888888

Email nasrul@unpad.ac.id;

marline.abdassah@unpad.ac.id

\begin{abstract}
Recurrent aphthous stomatitis (RAS) is a disease marked by painful oral lesions on the buccal and labial mucosa or tongue. Drug delivery systems (DDS) for RAS include topical forms that manage wound healing, cover the ulcer, and relieve the associated pain. DDS targeting the oral mucosa face a major challenge, especially the short residence times in the mouth due to the effect of "saliva wash-out", which continually removes the drug. The objective of this review is to study the development of preparation forms and delivery systems of various types and preparations that have been used for RAS management from 1965 until February 2020. There are 20 types of DDS for RAS which were discussed in 62 articles. The preparations were classified into 4 preparation forms: liquid, semi-solid, solid, and miscellaneous. In addition, the ultimate DDS for RAS preparations is the semi-solid forms (41.94\%), which include 5 types of DDS are gel, paste, patch, cream, and ointment. This preparation was developed into new preparation form $(11.29 \%)$, such as adhesive alginates, dentifrice, OraDisc, membranes, bioresorbable plates, pellicles, and gelosomes. Generally, the mucosal drug delivery system is the method of choice in RAS treatment because the ulcer is commonly located in the oral mucosa. In conclusion, these preparations are designed to improve drug delivery and drug activity for the treatment of RAS ulcers. Moreover, almost all of these DDS are topical preparations that use various types of mucoadhesive polymers to increase both residence time in the oral mucosa and pain relief in RAS treatment.
\end{abstract}

Keywords: drug delivery system, DDS, recurrent aphthous stomatitis, RAS, mucoadhesive, residence time

\section{Introduction}

Recurrent aphthous stomatitis (RAS) is a disease marked by painful oral lesions on the buccal and labial mucosa or tongue. Jurge et al revealed that RAS is mostly occurring on mucosal about $5-60 \%$ in the $\mathrm{UK}^{1}$ and around $2-50 \%$ worldwide. However, the exact cause of RAS is yet to be discovered, the symptoms start with a burning sensation (the first stage, namely pre-aesthesia) followed by the pre-ulcerative stage, in which the epithelium is infiltration by lymphocytes. The next step is the ulcerative stage, in which edema develops, followed by localization of keratinocytes and localized vasculitis, which causes local inflammation, ulceration, and the infiltration of plasma cells, lymphocytes, and neutrophils. These immune responses lead T cells and other leukocytes, namely macrophages and mast cells, to release tumor necrosis factor-alpha (TNF- $\alpha$ ); this is the final stage of RAS, which includes the healing process. ${ }^{2}$ Current treatment of RAS is aimed at ulcer re-epithelialization and reducing mucosal surface inflammation. 


\section{Graphical Abstract}

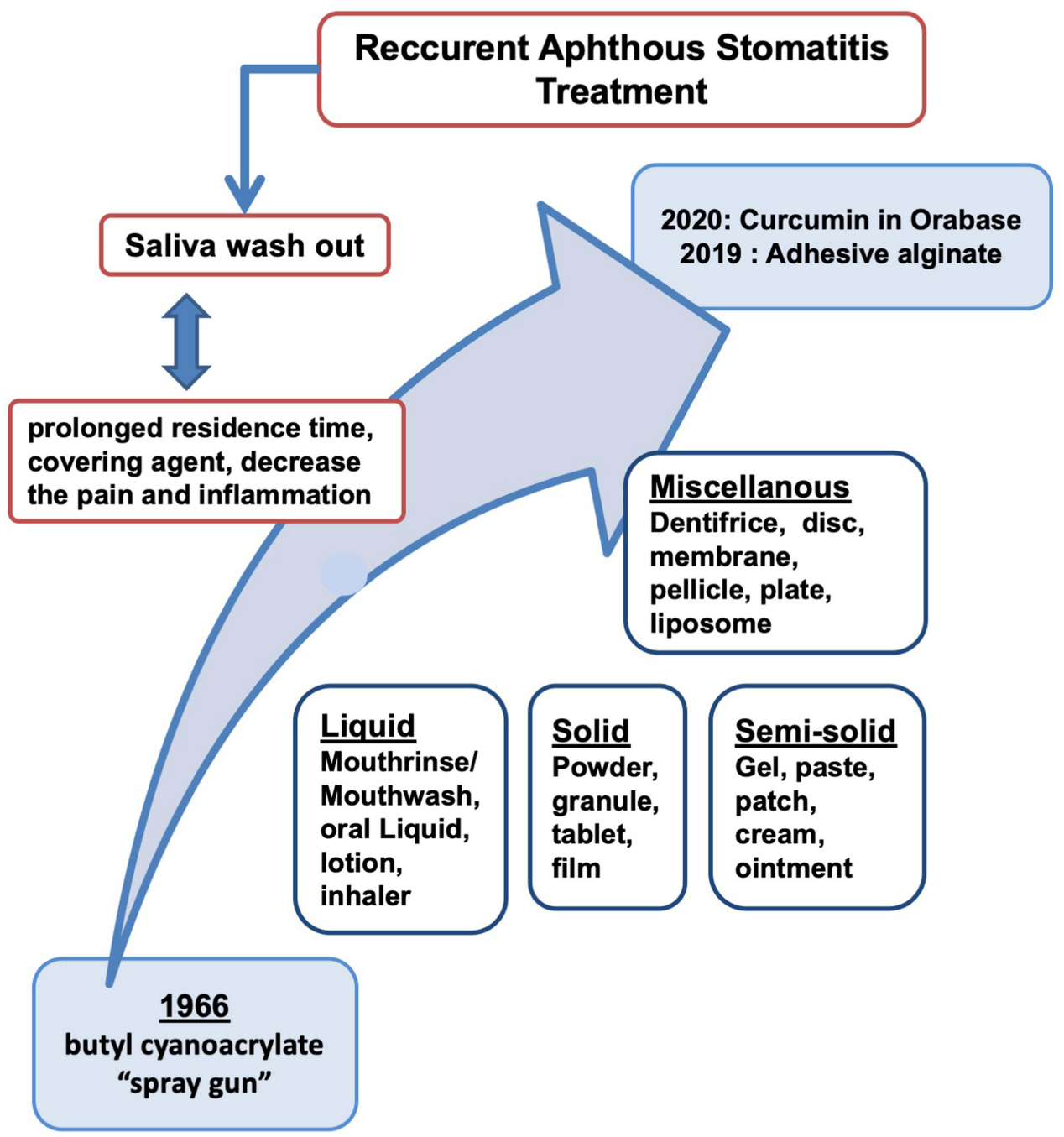

A drug delivery system (DDS) is a mechanism of drug administration through various routes of an organ in humans or animals to enhance the therapeutic effect. ${ }^{3}$ The DDS for RAS treatment evolved in the past. The most common RAS were found in the mucosa about $83 \%$ and the least in the gum, tongue, and floor of the mouth, ${ }^{4}$ Based on the structure of the mouth and the prevalency of RAS, the DDS for RAS preparation focused on the mucosa. The mucosa, covering almost all oral surfaces, can use as an adhesive site to prolong the drug release resulting in a better therapeutic effect. A mucoadhesive drug delivery system has a great concern as one of the methods to deliver the active compound through mucosal membranes. The drug release at the oral mucosa is divided into two mechanisms, ie: extended drug release to give a local therapeutic effect, or fast drug release to get a systemic therapeutic effect quickly. The local therapeutic effect was found in the case of RAS preparation to release the drug at a proper rate. $^{5,6}$ RAS preparations have been developed in the past including the discovery of the active substance and the excipients used as a covering agent or healing agents.

The aim of this review is to study the various dosage forms used in DDS for RAS management both topical and systemic. This review describes the various DDS developed for RAS management from 1965 until February 2020. The first adhesive polymer was used in the dental military in 1965 with an applicator called a "spray gun". 7 The discovery following by a clinical trial of Listerine in 1991, a well-known mouthwash 
brand in Indonesia. ${ }^{8}$ The latest study is adding 1-ethyl3-(3-dimethylaminopropyl) carbodiimide hydrochloride (EDAC) as a coupling agent to bind L-cysteine to form adhesive alginate, and forming an alginate-chitosan scaffold in hydrogel film formulation as a DDS for $\alpha$ mangostin for RAS therapy. ${ }^{9,10}$

\section{Methodology}

The review was conducted using the Scopus database with the keywords: recurrent aphthous stomatitis preparation. The studies from 1965 to February 2020 obtained 763 articles related to RAS preparation. There were 264 articles, and several types of preparation were selected. The excluded articles are 193 articles including reviews or original research that are not related to the subject such as pharmacological and clinical studies of RAS. The total number of articles included is 62 articles, which were about the development of drug delivery systems for RAS management (Figure 1).

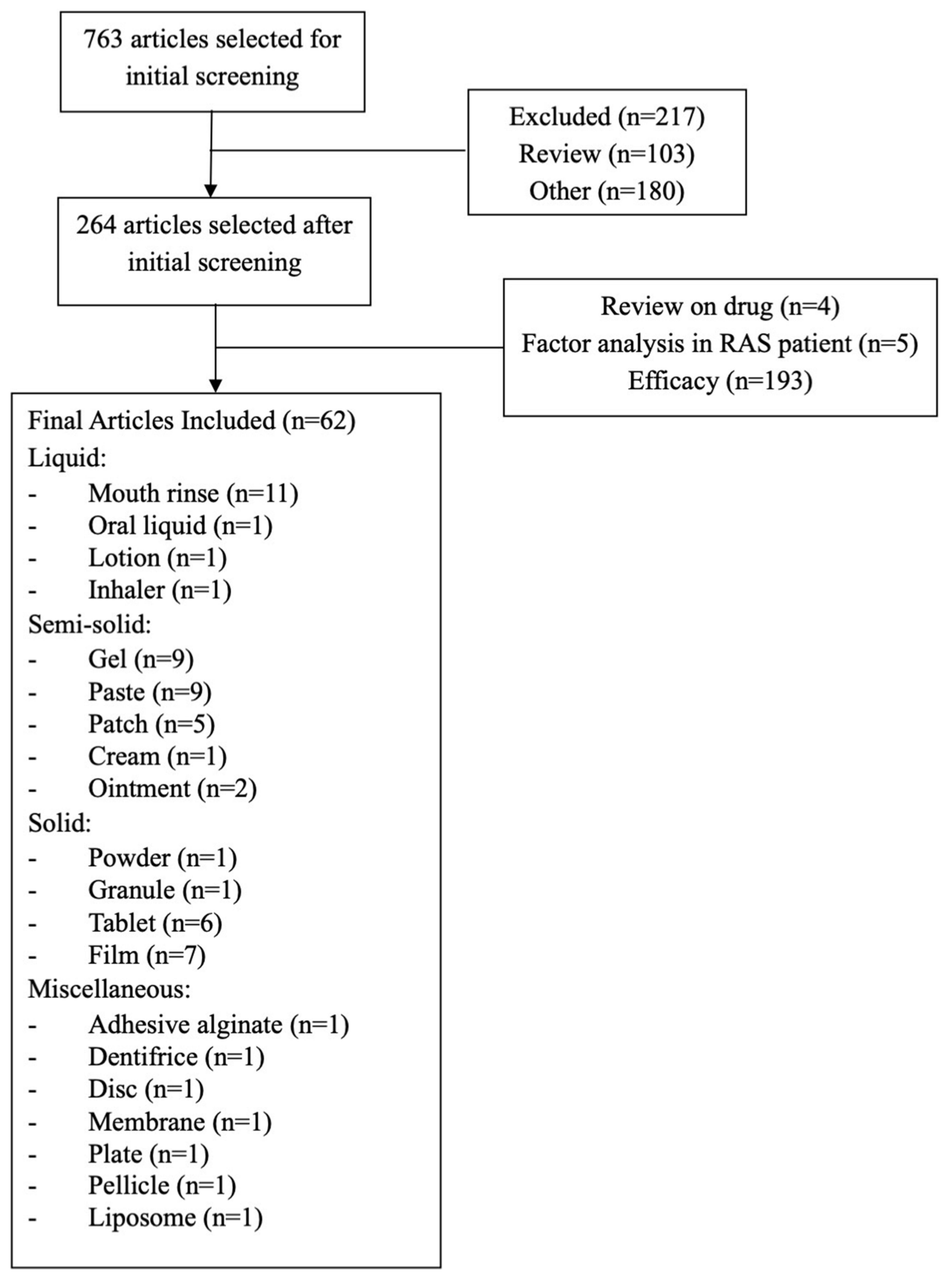

Figure I Flowchart of the methodology used in this review. 


\section{Recurrent Aphthous Stomatitis}

The term "aphtha" originating from the Greek "aphthi", which means a burning sensation or inflammation. This term is dedicated to Hippocrates, who used the words for the first time to describe these mouth disorders. ${ }^{11}$

Histopathologically, aphtha is characterized by a burning sensation in the pre-ulcerative stage (pre-aesthesia), which is followed by pre-ulcerative stage, where the epithelium is infiltrated by mononuclear cells (lymphocytes). Edema then develops, followed by localization of keratinocytes and localized vasculitis, causing local swelling leading to ulceration and infiltration by plasma cells, neutrophils, and lymphocytes in the ulcerative stage. The final step is epithelial mucosal regeneration in the healing process (Figure 2). ${ }^{2}$

The cell-mediated immune response, through TNF- $\alpha$ released as a main inflammatory cytokine, implicates T-cells and other leukocytes, including mast cells and macrophages. ${ }^{12}$ TNF- $\alpha$ has chemotactic activity on neutrophils that cause inflammation and the release of Major Histocompatibility Complex (MHC). This phenomenon causes damage to epithelial cells through cytotoxic T cells (CD8+), Interleukin (IL) such as IL-2, IL-6, IL-10, and IL-1 $\beta$. Gamma delta $(\gamma \Theta)$ T lymphocytes are important in the release of antibodies mediated by cytotoxic reactions in the epithelium of the oral mucosa. ${ }^{13}$ The factors affecting the inflammatory processes during RAS are described in Figure 2.

\section{Discussion}

\section{History}

The first publication of a new adhesive polymer application for oral ulcer and a periodontal preparation is an adhesive dressing of butyl cyanoacrylate. ${ }^{14}$ The dressing was applied to the human oral cavity using a "spray gun". This preparation was made to reduce the pain or discomfort in the oral mucosa, and repair the mucosal tissue in patients with periodontal disease, canker sores, leukemia ulcers, and following local extractions. This compound has the specific moiety $\mathrm{CH}_{2}=\mathrm{C}(\mathrm{CN})-\mathrm{COOR}$, which acts as a hemostatic agent by entering and absorbing into the tissue through phagocytosis by histiocyte cells. ${ }^{14}$ Butyl cyanoacrylate forms thin films that cover the surface of oral mucosal ulcers; therefore, oral fluids, food, and bacteria seep between the covering agent and healing tissue. Additionally, butyl cyanoacrylate also has potential as a surgical dressing, based on its property of inhibiting staphylococcus growth. $^{7}$

\section{Drug Delivery Systems for Recurrent Aphthous Stomatitis}

Various DDS for mouth preparations have been developed over the years. Sixty-two articles that studied various types of drug delivery systems for RAS treatment are described in Table 1. The DDS in the articles were classified into

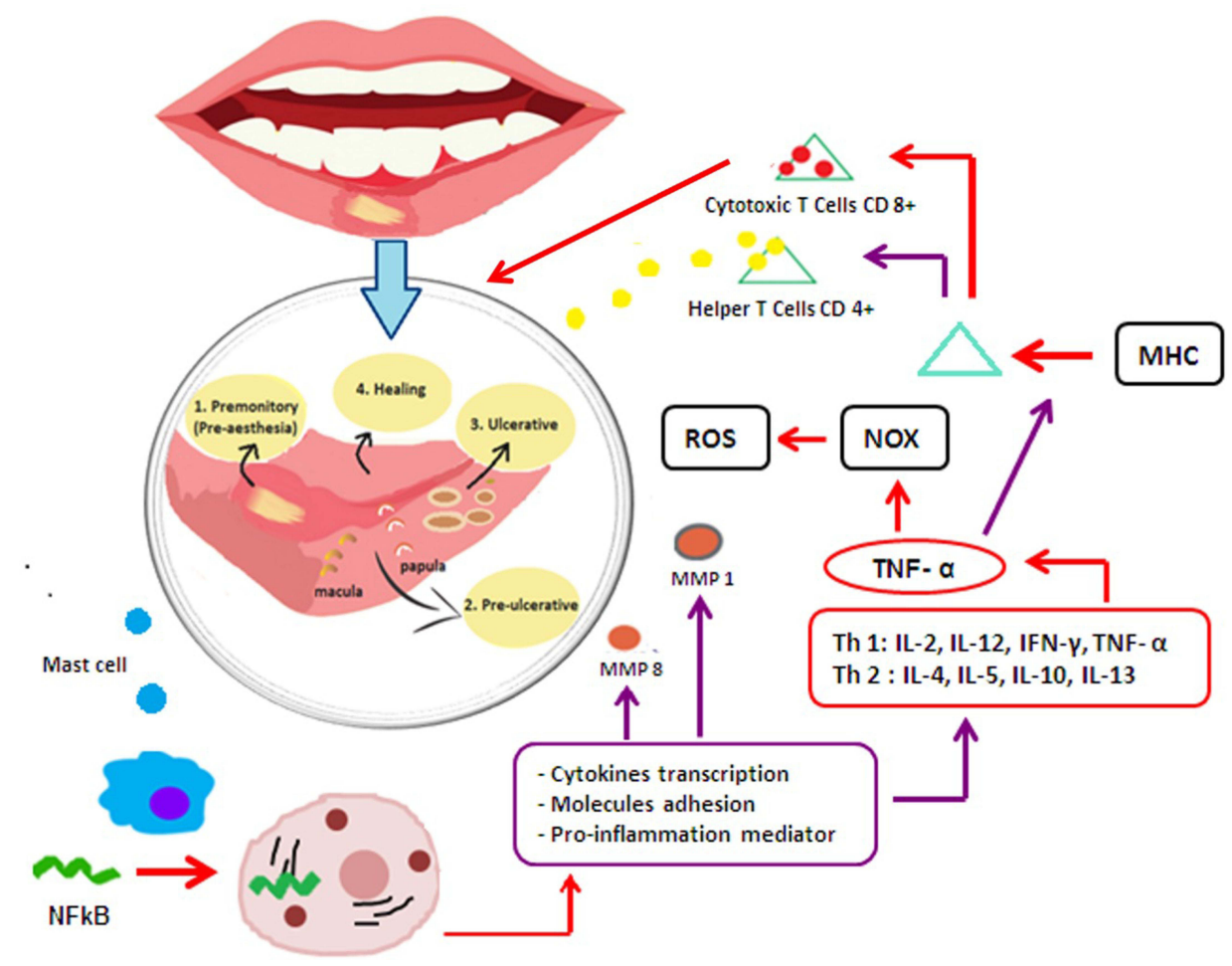

Figure 2 Inflammation process induced Recurrent Aphthous Stomatitis (RAS). 


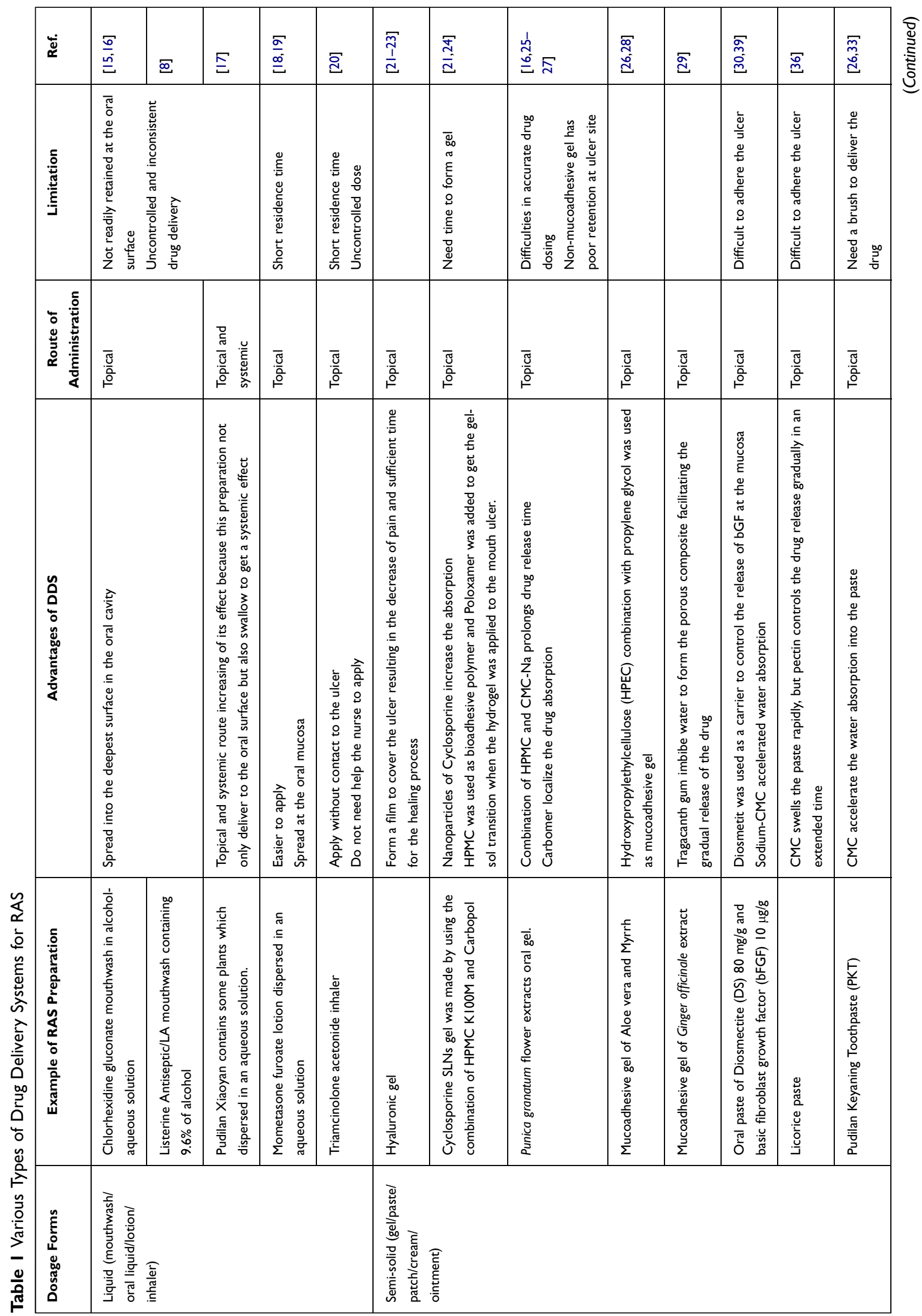




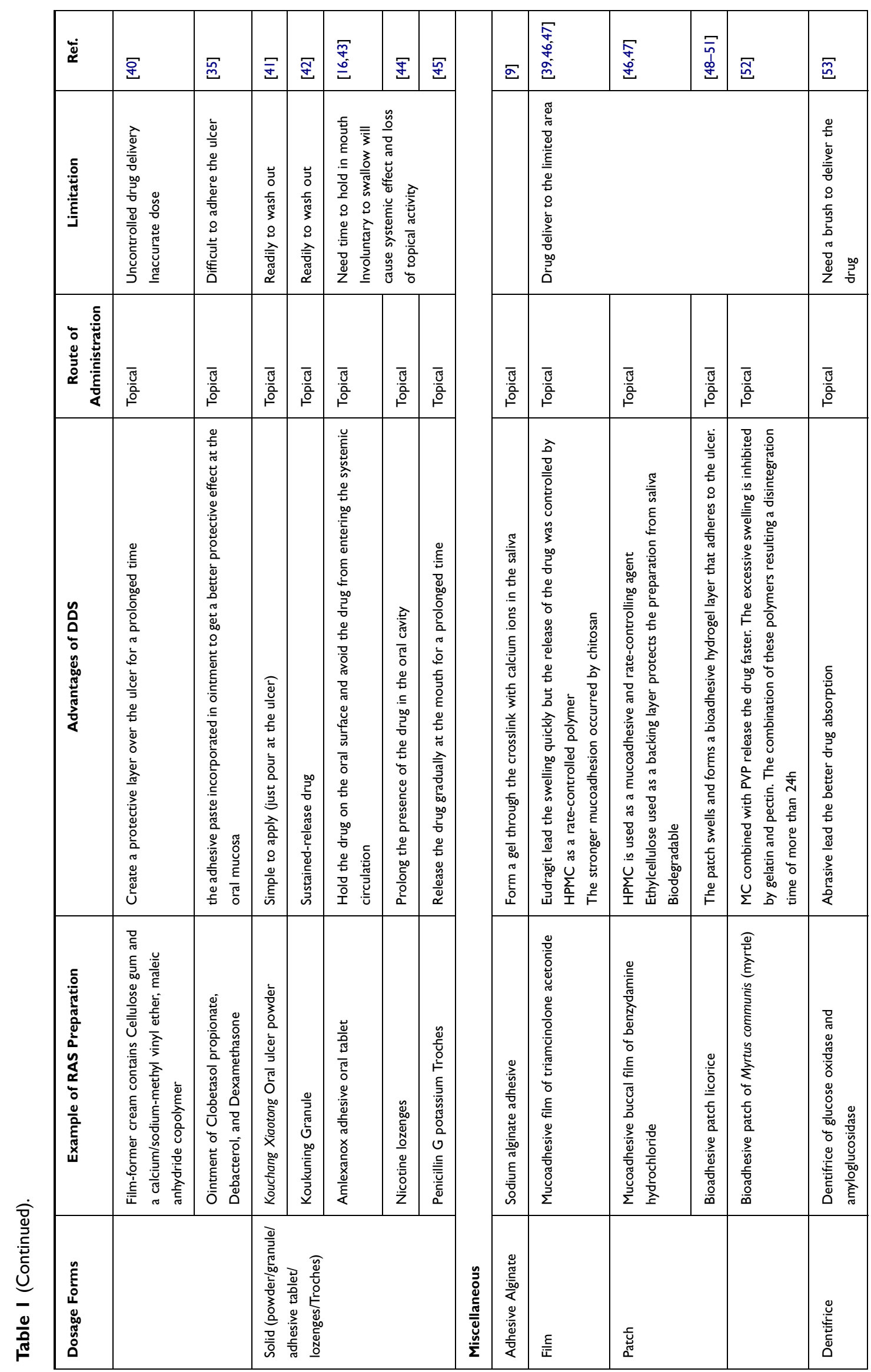




\begin{tabular}{|c|c|c|c|c|}
\hline 跑 & 氙 & 畐 & $\begin{array}{l}\text { D. } \\
\stackrel{\infty}{n} \\
\stackrel{n}{n}\end{array}$ & 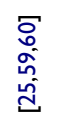 \\
\hline \multicolumn{3}{|l|}{ 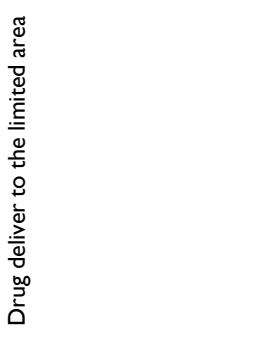 } & & \\
\hline 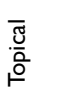 & $\begin{array}{l}\overline{\widetilde{\Xi}} \\
\stackrel{\bar{\varrho}}{\circ}\end{array}$ & 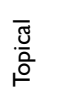 & $\begin{array}{l}\overline{\widetilde{\Xi}} \\
\stackrel{\bar{\circ}}{\circ}\end{array}$ & $\begin{array}{l}\overline{\widetilde{\Xi}} \\
\stackrel{\widetilde{\bar{a}}}{\circ}\end{array}$ \\
\hline 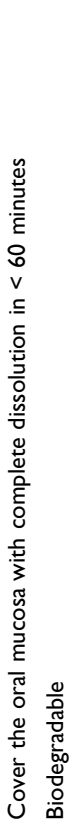 & 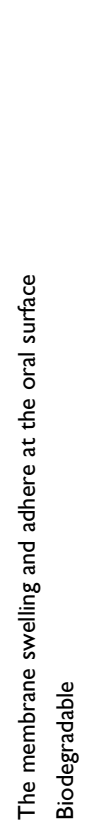 & 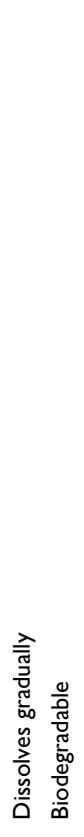 & 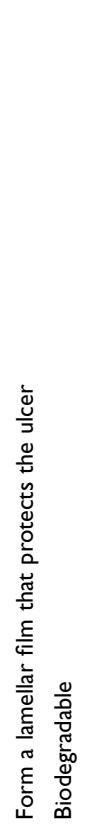 & 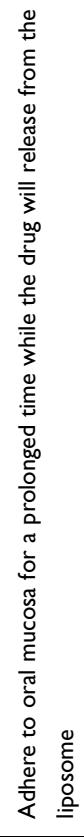 \\
\hline 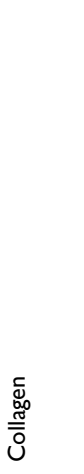 & 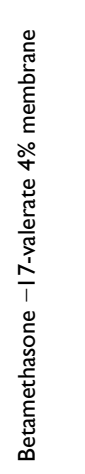 & 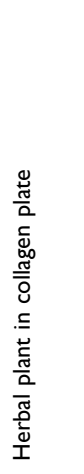 & 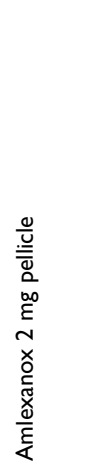 & 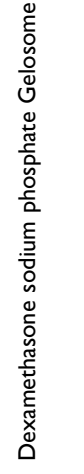 \\
\hline 亗 & 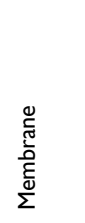 & 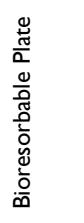 & $\begin{array}{l}\frac{0}{\underline{\underline{\underline{v}}}} \\
\frac{\bar{\alpha}}{\alpha}\end{array}$ & 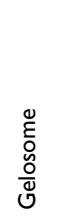 \\
\hline
\end{tabular}

four different preparation forms, specifically liquids, semisolids, solids, and miscellaneous.

\section{Liquids}

This review found that 14 (22.58\%) of the DDS for RAS were in liquid form (Figure 3). The liquid forms often used for RAS are mouth rinse/mouthwashes, oral liquid, lotion, and inhaler.

\section{Mouthrinse/Mouthwash}

Mouthwash is common preparation for RAS treatment for a long time. LA, a well-known brand of mouthwash in Indonesia, containing an antiseptic in aqueous solution, was first studied in $1991 .^{8}$ To date, this preparation form was still chosen because it is easy to apply and spread in the mouth. ${ }^{18,19}$

Mouthwash is a non-sterile medicated solution used for gargling and rinsing the mouth. Mouthwash is an aqueous solution containing alcohol in various concentrations between $18 \%$ and $26 \%$. Mouthrinse/mouthwash is one of the carriers for the topical oral drug due to its spreadability into the deepest surface in the oral cavity. ${ }^{61,62}$ Several oral disruptions necessitate the use of some mouthwash due to its deodorant, refreshing and antiseptic effects. An odorless mouthwash is often used for a periodontal disorder or the treatment of secondary oral infections. Mouthwashes are commonly designed to deliver antimicrobial agents (to reduce oral bacteria) and topical anti-inflammatory agents, as well as to remove remaining food in the mouth, act as topical analgesics, and prevent caries (fluoride), ${ }^{61,62}$ while the cosmetic mouthwashes are used to remove oral debris before or after brushing, to cover unpleasant odor, diminish microbes, and refresh the mouth with a pleasurable taste. $^{62}$

Mouthwash has been used as a vehicle for both herbal or synthetic active ingredients, such as Rosa damascena, ${ }^{63}$ Zataria multiflora, essential oils, ${ }^{64}$ and lactic acid. ${ }^{65}$

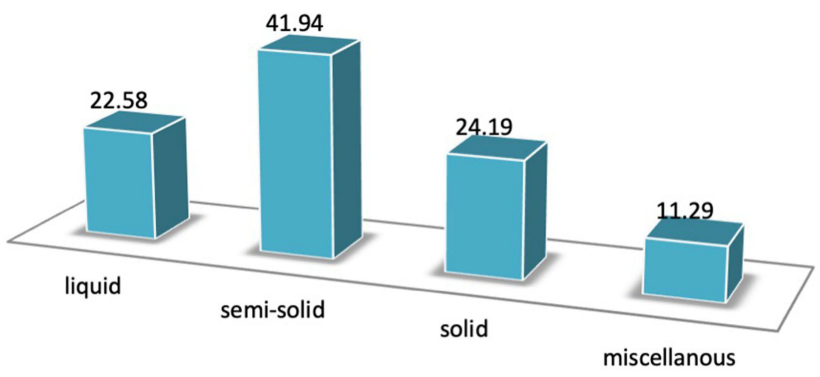

Figure 3 The number of preparation form used in DDS for Recurrent Aphthous Stomatitis (RAS). 
A mouthwash of $0.2 \%$ chlorhexidine gluconate inhibited plaque growth and decreased stain on the teeth. ${ }^{15} \mathrm{~A}$ mouthwash containing $0.25 \mathrm{~g} / 10 \mathrm{~mL}$ chlortetracycline (Aureomycin ${ }^{\circledR}$ ) decreased the number of ulcers and alleviating the sores. ${ }^{53}$ Minocycline $0.2 \%$ and tetracycline $0.25 \%$ improved pain control significantly by decreasing the duration and variation of pain. ${ }^{66}$

\section{Oral Liquids}

Oral liquids have been used to deliver the herbal in topical administration for RAS. The mechanisms were similar to mouth rinse/mouthwash. Oral liquid is different from mouthwashes because the oral liquid is not thrown away after gargling the oral cavity, but swallowed to get the systemic effect as an anti-inflammation. ${ }^{67,68}$

Pudilan Xiaoyan Oral Liquid (PDL) is a Chinese patented medicine that is described in "Pudilan" Traditional Recipes, which is recorded in the Chinese pharmacopeia. ${ }^{17}$ PDL is composed of Bunge Corydalis (Corydalis Bungeana), Indigowoad Root (Isatis Indigotica), Scutellaria Amoena (Scutellaria Baicalensis), and Mongolian Dandelion (Taraxacum Mongolicum). The last study in vitro and in vivo suggested the antiviral effect of Pudilan Xiaoyan oral liquid against Covid-19. ${ }^{68} \mathrm{PDL}$ is a traditional anti-inflammatory medicine that can reduce pro-inflammatory mediators, such as NF- $\kappa \beta$, IL-10, and TNF- $\beta .{ }^{17}$ PDL was also studied in RAS patients, demonstrating that the curative effect of Pudilan was significant, shown through reduced healing times and pain relief without any adverse reactions. ${ }^{67}$

\section{Lotions}

Lotions are emulsified solutions generally intended for external application. Lotion is formulated by an addition of some excipients, such as:

- Alcohol, as co-solvent and coolant

- Humectants, to keep moisture after application, such as glycerol

- A vehicle, purified water

- Buffer, to maintain $\mathrm{pH}$

- A preservative can be used in lotions because the formulation is a suspension or emulsion

- A Stabilizer or suspending agent, to maintain the stability of the formulation ${ }^{19}$

Lotions may contain some polymers as a suspending agent. The polymer can adhere to the oral mucosa and increase the retention time of the drug in the oral cavity. ${ }^{18,19}$ Lotion has been used as DDS for mometasone furoate in RAS preparations, as this preparation is easier to apply than gels or pastes that have problems adhering to the mucosa. ${ }^{18}$

\section{Inhalers}

The interaction of mucin and water-soluble polymer underlying the development of mouth inhalers for aphthous ulcers. Mucin, which covers all surfaces of the oral mucosa, has the potential to be used to deliver the drug and retained in the oral cavity. Inhaler preparation has been used to deliver corticosteroid into the oral mucosa. Patients were advised to use an inhaler directly over the lesion and deliver the dose. The polymers such as chitosan, gum, amylose, and cyclodextrin have been investigated for sustained drug delivery system. ${ }^{69}$

This preparation was chosen to deliver Irsogladine maleate for oral ulcers because the common preparation such as mouthwash sometimes induces nausea and vomiting. ${ }^{70}$ Therefore, inhalers were the better choice to deliver the drug without contact with the ulcer. ${ }^{69}$

Triamcinolone acetonide inhaler was used to treat RAS ulcers of HIV patients because they do not need help from the pharmacist to compound the drug or a nurse to apply the drug. ${ }^{20}$

The spreadability of the inhaler will cover almost all oral surfaces, mainly the oral ulcer. The drug is not readily absorbed, but adhering in a sufficient time over the mucosa. This interaction will prolong the retention time of the drug in the ulcer to promote the healing process. ${ }^{20}$

\section{Semi-Solids}

There are 26 (41.94\%) articles regarding RAS preparation in semi-solid form (Figure 3). These preparation forms consist of gel, paste, patch, cream, and ointment. Semisolid form was chosen because the use of polymers increases the residence time at the oral mucosa compared to liquid which rinses quickly because of the effect of "saliva wash out".

\section{Gels}

Gels are a semi-solid preparation that has a spreading ability and a cooling effect due to the humectants in the preparation. Gels form a three-dimensional network by interactions between colloidal particles and the vehicle. Gel can use aqueous, non-aqueous, hydroalcoholic, or alcohol solution as the vehicle. ${ }^{19}$

Hyaluronic acid was discovered as a hydrophilic polymer in 1934 and it is now widely used in dermatology, 
ophthalmology, and rheumatology. HA is used as an active ingredient in dermatology for treating edema and wounds due to its anti-inflammatory activity. ${ }^{70,71}$ Additionally, HA is also used as a vehicle for topical DDS. ${ }^{72}$

HA is applicable in wound healing due to its antiinflammatory effect. One study investigating the effect of a $0.2 \%$ HA gel preparation on RAS resulted in a healing effect on the RAS ulcers. ${ }^{22-24}$ HA gels $0.2 \%$ covering around of oral cavity to protect the ulcer from the environmental effect such as saliva, food, etc. ${ }^{21,24}$ The topical gel of HA formed a barrier over both minor and RAS herpetiform ulcers, resulting in decrease of pain and faster healing times. ${ }^{21,24,73}$

This mechanism is also applied in the gel containing HPMC to deliver CsA-loaded SLNs at the ulcer site. CsA SLNs were made to increase the drug delivery at the ulcer site. Poloxamer was added as a thermoreversible polymer to gel-sol transition when the hydrogel was applied to the oral ulcer. $^{21,24}$

Aslani et al developed an oral gel containing a flower extract from Punica granatum. The oral gel was made by using two cellulose polymers, i.e CMC-Na, and HPMC. Carbomer 934, triethanolamine, potassium sorbate, polyethylene glycol (PEG) 400, ethanol, gallic acid, and sodium carbonate were used as excipients in the formulation. $^{74}$ The use of cellulose polymer (HPMC and CMC-Na) in combination with Carbomer will increase the mucoadhesive ability of the preparation. The combination of HPMC and CMC-Na prolongs the drug release time compared to each gel preparation. Carbomer was added as a mucoadhesive agent by localizing the drug absorption resulting in a higher drug concentration at the ulcer. Thus, the combination of these polymers increases both retention time and drug concentration at the site of the ulcer. ${ }^{25-27}$

Mucoadhesive buccal gels are intended to provide a comfortable preparation when applied to RAS ulcers at the mucus membranes, including the tongue, gingiva, lips, and cheek. HPMC is used as a mucoadhesive agent to deliver benzydamine hydrochloride as an oral antiseptic by adhering and controlling the drug release in the mucosa. ${ }^{39,46}$ The other cellulose polymer used in RAS therapy is hydroxypropylethylcellulose (HPEC). ${ }^{28}$ This gel was used as the DDS for Aloe vera and myrrh due to its mucoadhesive properties and control of the drug release. ${ }^{26,28}$

Topical drug preparations for RAS treatment, such as ointments, patches, mouthwashes, and other topical DDS, are recommended due to the systemic effects. ${ }^{12,75}$ Some studies have been conducted for this purpose, such as the use of mucoadhesive agents as a vehicle of the drug to allow sufficient time for the drug to activate its therapeutic effect. $^{76,77}$

Mucobioadhesive gels may contain herbal ingredients available in traditional Iranian medicine. One of these herbs is the ginger extract, intended to relieve the pain associated with RAS ulcers. Mucobioadhesive bases are made by using tragacanth gum and adding alcohol, sodium benzoate, and distilled water. Ginger is extracted in alcohol and then dried and mixed with the base. Tragacanth gum is a hydrophilic colloid that can imbibe the amount of water resulting in the porous composite form resulting in the gradual release of the drug in the site of action. ${ }^{29,78}$

Orabase containing Curcumin 5\% is similarly effective to triamcinolone acetonide $0.1 \%$ for RAS ulcer therapy. Curcumin has anti-inflammatory effects through inhibition of both cyclooxygenase and lipoxygenase, resulting in regulation of iNOS function. Curcumin decreases the release of TNF- $\alpha$, IL- $1 \beta$, and IL-6. Other studies have shown that curcumin gel $1 \%$ and $2 \%$, are effective for RAS therapy. Curcumin extract was incorporated into mucoadhesive orabase to increase the adhesiveness of the preparation with oral mucosal in a sufficient time to give the therapeutic effect at the ulcer site. ${ }^{79}$

\section{Pastes}

The paste was made using a DDS for a Diosmectite and basic Fibroblast Growth Factor (bFGF). Diosmectite was added as a carrier to control the release of bGF at the mucosa. When the paste is applied to the ulcer, Diosmetit forms a film as a protective agent covering the ulcer from the physical and chemical effects. Diosmetit is also able to absorb other factors of RAS such as microorganisms and toxins. ${ }^{30}$ In combination with HPMC, this preparation will increase the retention time at the oral mucosa and control the drug release. ${ }^{39}$

Amlexanox 5\% in an oral paste decreases the healing time of RAS ulcers through its anti-inflammatory activity.31,32 The oral paste containing Amlexanox was designed as a new alternative for RAS treatment. CMC-Na was used as a base in the oral paste because the presence of sodium ions leading to crosslinking in the polymer to form the polyelectrolyte complex and increase the water uptake into the molecule, called the Donnan effect. ${ }^{26}$ The combination with methylcellulose (MC) increases the activity of this preparation, because $\mathrm{MC}$ is a thermoresponsive polymer that constructs the phase-transition to the stronger adhesiveness of the preparation. ${ }^{80}$ 
A buccal paste containing propolis was made using beeswax, pectin, and CMC as a base, and the other excipients, including methylparaben, propylparaben, gelatin, ethanol 96\%, olive oil, and sesame oil. ${ }^{34}$ Pectin was added to CMC paste to control the drug release. When CMC swells, the drug will go out from the DDS rapidly. In the presence of pectin, the drug will be released in a controlled manner to maintain the effect of the drug at the ulcer site with sufficient time. ${ }^{81}$

Licorice is an Iranian herbal medicine widely used to relieve pain and decrease the necrotic zone of RAS ulcers. Topical steroids are still the best choice for RAS therapy; however, there are several side effects associated with their use, including systemic absorption, fungal infection, and mucosal disruption. Licorice contains glycric acid, which can inhibit the enzymatic action of cyclooxygenase and lipooxygenase. Besides this, licorice can inhibit the production of Reactive Oxygen Species (ROS) and prevent the cell immigration process, leading to the inhibition of the metabolism of arachidonic acid. All of these mechanisms result in a decrease in inflammation. ${ }^{36,82}$ Licorice extract was suspended in gelatin to form a matrix system contains $\mathrm{CMC}$ and pectin which controlled the drug release at the ulcer site. CMC can swell rapidly, allowing the drug to be released gradually in an extended time. ${ }^{81}$ The evaluation demonstrated that this topical preparation has a faster healing and significant beneficial effect on pain therapy and ulcer size, without any side effects. $^{36}$

In other paste, gelatin was added to CMC-gelatin to increase the adhesiveness in the oral mucosa. This preparation is called oromucoadhesive paste. ${ }^{37}$ The paste was made with the addition of Plastibase ${ }^{\circledR}$. Plastibase ${ }^{\circledR}$ is made by using mineral oil and polyethylene in a ratio of 95:5, respectively. In this formulation, Plastibase ${ }^{\circledR}$ is made with HDPE and LDPE. ${ }^{37}$ The first step in designing a formulation to get the optimum concentration of Plastibase ${ }^{\circledR}$. The next step was the pre-formulation stage, to get the optimum concentrations of $\mathrm{CMC}-\mathrm{Na}$, pectin, and gelatin. ${ }^{37}$ Gelatin was used as a matrix system in this DDS. With the combination with pectin, the drug release will be controlled at the ulcer site to maintain the effect of the drug in a sufficient concentration and time. ${ }^{81}$

In addition, the toothpaste facilitates the DDS for RAS management. Pudilan Keyaning Toothpaste (PKT) is a toothpaste containing Pudilan Keyanning extract with sodium-CMC as a base. PKT is made through the addition of other herbal ingredients, such as propolis, gallnut, Isatis root, dandelion, Scutellaria baicalensis, and Bunge corydalis, which have already been used for long periods in traditional Chinese medicine. ${ }^{33,69}$ Furthermore, Pudilan Keyaning applied in toothpaste has potential use in the treatment of RAS ulcers. CMC-Na was used as a base in this delivery system to increase the healing effect of Pudilan Keyaning. CMC-Na as a base and other excipients, including polyethylene glycol, sodium lauryl sulfate, glycerol, xanthan gum, glucide, sorbitol, silica gel, silica gel type 203, silica gel type 153, flavors, soluble propyl hydroxybenzoate, nipabutyl sodium, and sodium hydrate. Pudilan Keyaning showed increased healing rates of RAS ulcers by accelerating the water absorption into the paste to swell. When the paste swells, the drug starts to be released from the preparation, thus, acts directly on the site of the ulcer. ${ }^{26,33}$

\section{Patches}

Bioadhesive patches containing licorice were studied for RAS treatment. ${ }^{48}$ Tragacanth gum was used as a base resulting in significant reduction of the ulcer size. ${ }^{83}$ Licorice bioadhesive patches have mechanical properties to protect the ulcer and anti-inflammatory activity. ${ }^{50}$ When the dry patches are applied to the surface of RAS ulcers on the mucosa, the patches come in contact with saliva, causing them to swell and form a bioadhesive hydrogel layer that directly adheres to the ulcer. ${ }^{48-51}$

Nicotine patch was formulated by using polyacrilex gum and provides a prolonged time of constant drug concentration in the blood. Treatment using a $14 \mathrm{mg}$ nicotine patch every 24 hours decreased the duration of RAS ulcers. After a month, the respondents stopped applying the patches and several ulcers appeared within a week. However, when the patch was used, these ulcers quickly disappeared. ${ }^{84,85}$

Oral patches containing Myrtus communis (myrtle) were developed by the combination of gelatin, pectin, PVP, and MC. ${ }^{52}$ Mucoadhesive oral patches consisting of myrtle were made using the solvent casting method. ${ }^{86} \mathrm{MC}$ combined with polyvinyl pyrrolidone PVP to release the drug faster. The excessive swelling ratio caused by PVP is inhibited by the addition of gelatin and pectin. Pectin also increases the tensile strength, while gelatin has the opposite effect. The combination of MC, PVP, gelatin, and pectin in the myrtle patch resulting in a disintegration time of up to $24 \mathrm{~h}$ and more. ${ }^{52}$

Electrospun mucoadhesive bilayer patches of clobetasol-17-propionate were made by using electrospinning 
equipment with certain specifications for the syringe pump, power source, voltage, flow rate, etc. ${ }^{87}$ The mucoadhesive bilayer patch is composed of eudragit and PVP as a base. Polycaprolactones in dichloromethane: dimethylformamide (90:10 vol\%) was used as a backing layer. In vitro study showed that this DDS resulted in the drug release up to $80 \%$ at 6 hours and in vivo residence time of about 3 hours. Eudragit in the patch causes the swelling to occur quickly but is able to release the drug in a long time. The backing layer is adequate to hold the preparation for a prolonged time at the ulcer site. ${ }^{47}$

The popularity of MDFs has increased due to their wide and varied advantages and the convenience to use in pediatric and geriatric patients. Most of the polymers used in MDFs are an amorphous dispersion of active substances tangled up in the matrix. The other advantages are enhanced patient compliance and decreases the production cost. ${ }^{88}$ This preparation was made to release the drug faster. When this preparation makes contact with saliva, the system swells rapidly without the addition of water. The swelling matrix will release the drug into the ulcer at a certain time. ${ }^{88}$

\section{Creams}

AphtoFix $^{\circledR}$ is a film-forming cream that has protective properties similar to the previously discussed adhesive properties that increase the healing process of mouth ulcers. This preparation is a new formulation of oral ulcer cream that has been studied by Sakly et al. ${ }^{40}$

The advantage of this preparation is that AphtoFix ${ }^{\circledR}$ has adhesive properties due to the application of cellulose gum and a calcium/sodium-methyl vinyl ether, maleic anhydride copolymer, along with some physical property modifications used to make the saliva creating a thin and elastic pad that covers the sores. The cream application enables the drug to create a protective layer and remain resident as a layer over the site of the ulcer for a prolonged time. $^{40}$

\section{Ointments}

Clobetasol propionate was used in the study of ointments because of its high corticosteroid potency in topical applications. Based on this benefit, clobetasol propionate was delivered in the ointment preparation form. ${ }^{38}$ The DDS was made by mixing the drug with an adhesive paste (Orabase). In oral disorders such as RAS, 0.05\% clobetasol propionate ointment is incorporated into a base of orabase paste. $^{35}$ The orabase was used as a mucoadhesive agent to cover the oral surface. The adhesive paste is incorporated in ointment to get a better protective effect at the oral mucosa via increasing adhesiveness resulting in the prolonged retention time at the oral ulcer. ${ }^{35}$

\section{Solids}

In this review, only $16(12.90 \%)$ solid forms were used in RAS preparation. Solid forms are often used as DDS for RAS treatment including powder, granule, and tablets.

\section{Powders}

A fundamental theory of traditional Chinese medicine is that disorders in the oral mucosa may be caused by exogenous pathogenic toxins, excessive fire due to the lack of Yin, reducing the heat and inflammation. One of the traditional Chinese medicines suggested to play a role as a curative agent is Kouchuang Xiaotong powder, which is against heat, as well as detoxifying and eliminating inflammation, relieving pain, and eliminating the saprophyte. The main components of this powder are talcum, dragon's blood, and borneol. The preparation is applied in an appropriate amount with a cotton swab, by gently sweeping the ulcer area 3 times a day. Studies show that Kouchuang Xiaotong powder significantly relieves the pain and eliminates the local inflammation of ulcer while activating the microcirculation of local blood to trigger healing of the ulcer. $^{41}$

\section{Granules}

Koukining is a traditional medicine in China that has been used for a long time to medicate mouth ulcers. Koukining is composed of rhizoma coptidis, radix scutellaria, and other Chinese herbs. In this preparation, Koukining granules were made by wet granulation technology. The preparation of the granules was controlled to ensure the stable quality of the final products. Treatment of RAS ulcers with these granules was shown to be effective and worthy of clinical application. ${ }^{42}$

Granules were used as a drug delivery system as a carrier to deliver the herbal extract at the ulcer site. This system was built to get the sustained release drug. ${ }^{42}$

\section{Tablet}

The oral adhesive tablet of Amlexanox was used to treat mouth ulcers. The adhesive oral tablets were selected as a vehicle for the delivery of RAS drugs such as Amlexanox because they are easy to apply and carry a favorable taste. ${ }^{43}$ The tablet was designed to adhere to the surface of the oral mucosa. The interaction at the oral surface will result in the 
sustained release of the drug in a prolonged time. ${ }^{43}$ The clinical study showed that this new tablet system was effective both at decreasing the size of the lesions and the degree of erythema and at reducing the exudation level of the ulcer and alleviating pain.

The other study using Resveratrol as a prophylactic agent against inflammatory lesions in the oral cavity. The permeation study verifies the diffusion character of this drug into the buccal mucosa and predicts human behavior in vivo. The drug delivery system was designed to hold the drug on the oral surface and avoid the drug entering the systemic circulation. ${ }^{89}$

\section{Lozenges}

Lozenges containing nicotine were studied for oral and genital aphthae. The treatment began with an initial daily dose of $15 \mathrm{mg}$ nicotine for 12 weeks, displaying no adverse effects. Nicotine therapy was recommended in oral RAS treatment due to its protective effects through increasing oral mucosal keratinization, decreasing the pain and microbial infection. ${ }^{44,90}$ In some RAS patients, the treatment failed, resulting in side effects, including systemic effects. Nicotine lozenges were developed for systemic therapies because they are easy for patients to get over the counter at pharmacies or supermarkets. Nicotine lozenges available in two doses are 2 and $4 \mathrm{mg}$ or minilozenges with the lower doses of 1.5 and 4 mgn. ${ }^{44}$ Based on its molecular properties, nicotine acts to promote mucosal adhesion, angiogenesis, epidermal repair, wound healing, and reduced inflammation. The inflammation is reduced via two mechanisms:

- Regulating the expression of vascular EGF.

- Modulating the release of pro-inflammatory mediators due to local immune responses. ${ }^{44}$

\section{Troches}

Troches are the other DDS for RAS treatment that has some benefits. In an ethnic Chinese cohort, this preparation decreased the ulcer size and level of pain in RAS patients. Penicillin G potassium troches contain $50 \mathrm{mg}$ of magnesium stearate as a base, with the addition of other excipients. Almost all topical preparations stimulate secretion of saliva and wash out from the oral mucosa. Compared to other preparation forms, troches are commonly applied in RAS management. Study results demonstrate that the topical use of penicillin G potassium troches is able to reduce ulcer size and alleviate pain associated with RAS ulcers. ${ }^{45}$ The presence of saliva will initiate the wetting of the troches and soluble the drug gradually at the mouth in a prolonged time. ${ }^{45}$

\section{Film}

Films have been used as one of the new preparation forms for RAS therapy. There are $8(12.9 \%)$ articles describing the formulation and application of film in oral ulcer. A film can be developed into mucoadhesive preparation because the polymer base is able to adhere and swell when in contact with the mucosal surface resulting in the increase of residence time and prolonging the drug release. ${ }^{91}$

The major purpose of RAS management is to reduce the ulcer size and pain. The level of pain is a single indicator that relates to the size and clinical condition. This drug delivery system was used to deliver the drug into the oral mucosa using the adherence ability of a polymer to the mucosal surface of the mouth. ${ }^{92}$

An example of this preparation is mucoadhesive film of triamcinolone acetonide. Preparations of triamcinolone acetonide mucoadhesive films are made using the solvent casting method and consist of two layers. The first layer is made of combinations of HPMC, K4M, and K15M, with chitosan and Eudragit RL100 and the addition of glycerin. Propylene glycol is added as a plasticizer. The second layer contains ethyl cellulose. This DDS demonstrated high flexibility and maximum adhesion to the mucosa; however, almost all the films shrank. The formula containing HPMC K15M produced a zero-order drug release pattern. On the other hand, formulations containing chitosan followed non-Fickian zero-order release kinetics. Compared to chitosan and HPMC, Eudragit was less adhesive to the mucosa ${ }^{93}$ Eudragit in the film will result in the swelling to occur quickly, allowing the release of the drug in a controlled manner by HPMC as a rate-controlled polymer. ${ }^{39,46,47}$ Strong mucoadhesion occurs by chitosan, which has a positive charge interacting with sialic acid in the mucosal surface. ${ }^{55}$

Buccal mucosa is one of the mucoadhesive regions with potential for topical drug delivery. Mucoadhesive buccal films have been made using hydroxypropylmethylcellulose as a base and benzydamine hydrochloride as the active ingredient, a drug that has been used for a long time to treat RAS. This preparation was equipped with a backing layer containing ethylcellulose and the preparation was evaluated for ex vivo mucoadhesive time, mucoadhesive power, and in an ex vivo medication penetration study. The presence of HPMC as a polymer base causes the 
preparation to have sufficient physicochemical properties to provide a prolonged residence time of the drug on the surface of the buccal mucosa, while the backing layer holds the preparation for a prolonged time at the ulcer site. ${ }^{46,47}$

Buccal bilayer mucoadhesive films have been made using sodium alginate in addition to gellan gum. These films also contain $1 \mathrm{mg}$ of prednisolone sodium phosphate. Formulation of these films was done using the solvent casting method. The film is a bilayer thin film with sufficient flexibility for enough water-absorbing ability, mucoadhesive activity, and possesses good mechanical characteristics. The in vitro drug is released following non-Fickian diffusion. In vivo evaluation in rabbits with induced oral ulcers demonstrated that application of this preparation once daily for 4-5 days was completed the healing process and the ulcer disappeared. Histological analysis showed that the inflammation disappeared during the evaluation. ${ }^{91}$ The combination of sodium alginate and gellan gum enhances the mucoadhesive property and water absorption. The film swells and releases the drug into the ulcer at a prolonged time. ${ }^{91}$

The hydrogel film is the latest preparation form that was made for RAS therapy. The combination of two mucoadhesive polymers, i.e. sodium alginate and chitosan were used as the drug delivery for $\alpha$-mangostin. $\alpha$-Mangostin is one of the xanthones that was isolated from mangostin rind (Garcinia mangostana L.), one of the Indonesian native plants, which has been used in traditional medication. One of $\alpha$ Mangostin activity is an anti-inflammation leading the use of this compound in RAS management. ${ }^{10}$ Sodium alginate and chitosan are used as a matrix to deliver $\alpha$ mangostin for RAS therapy on the oral surface. Chitosan act as a cation which leading the polyelectrolyte complex formation with sodium alginate. $\alpha$ mangostin was entrapped in the matrix system, and released from the hydrogel film when the film swelling. When the hydrogel film is in contact with saliva, the film will adhere to the oral surface because of the interpenetration of sodium alginate molecule, but not readily disappear because of the presence of chitosan increasing the retention time through the interaction of chitosan with sialic acid in the oral mucosa forming a gel that covers the RAS ulcer in an extended time to release $\alpha$-mangostin. ${ }^{10}$

\section{Miscellaneous}

\section{Adhesive Alginates}

As recent as 2019, alginate adhesives have been developed for buccal aphthae drug delivery to increase drug retention time in the oral mucosa. An adhesive alginate scaffold is made by adding EDAC as a coupling agent to bind to L-cysteine. EDAC has a primary amino group with cations that interact with the carboxylic groups of alginate molecules. EDAC $50 \mathrm{mM}$ was mixed with $1 \%$ alginate; then, hydrochloric acid (HCL) was added at a concentration of $0.1 \mathrm{M}$ to adjust the $\mathrm{pH}$ to approximately 6.0 . The polymer obtained was then dialyzed using a $\mathrm{Nadir}^{\circledR}$ membrane to separate excess unbound sulfhydryl anions; the excess was first washed off with water containing $1 \mathrm{mM} \mathrm{HCl}$, then washed twice using $1 \mathrm{mM} \mathrm{HCl}$ and $1 \% \mathrm{NaCl}$, and, finally, washed five times using $1 \mathrm{mM} \mathrm{HCl}$. Furthermore, the samples were lyophilized at a temperature of $-30^{\circ} \mathrm{C}$ and pressure of approximately 0.01 bar. The resulting lyophilisate was stored at $4^{\circ} \mathrm{C}$. Sulfhydryl anchored alginate was formed by amide bonds through covalent bonding between the alginate and L-cysteine, with the presence of EDAC as a coupling agent. ${ }^{9}$

This modified alginate was applied in an oral disc containing ambroxol as a model. The disc was formed by a single-punch eccentric press (Paul Weber, Germany). The disintegration time of this preparation showed that sulfhydryl anchored alginate disc was prolonged about 3.52-fold and the bioadhesive was improved 11.56-fold compared to the native alginate. The release of ambroxol revealed 1.4-fold while the permeation was increased 1.89 -fold compared to the native alginate. ${ }^{9}$

\section{Dentifrice}

Zendium is a dentifrice containing enzymes. Zendium formulated in dentifrice form as a vehicle to carry both glucose oxidase and amyloglucosidase enzymes. Zendium was made by the addition of sodium fluoride at a concentration of $1000 \mathrm{ppm}$. The resulting $\mathrm{pH}$ of this preparation is 5.9, while the $\mathrm{pH}$ of placebo containing $1000 \mathrm{ppm}$ of sodium fluoride without enzymes is 6.4 , in the range of normal $\mathrm{pH}$ of saliva. ${ }^{94}$ The abrasive effect of the preparation will result in better drug delivery at the ulcer site. ${ }^{53}$

\section{Disc}

The OraDisc ${ }^{\mathrm{TM}}$ is one of a patch that is used to deliver $2 \mathrm{mg}$ of amlexanox for oral ulcers due to the antiinflammatory activity. Amlexanox OraDisc ${ }^{\mathrm{TM}}$ is a new formulation that was developed from 5\% amlexanox 
paste. OraDisc ${ }^{\mathrm{TM}}$ is a bioerodible mucoadhesive patch designed to increase drug release at the target site. This preparation forms a thin and flexible film, containing a backing layer and a drug layer with mucoadhesive ability. The preparation is approximately $1.5 \mathrm{~cm}$ in diameter and contains $2 \mathrm{mg}$ of amlexanox. The active site of the disc is layered to adhere to and cover the oral mucosa with complete dissolution in $<60$ minutes. The patch is swollen by the end of the process and is removed via washing with salivary fluid. ${ }^{54}$

\section{Membranes}

The membranes were made as a vehicle to deliver betamethasone valerate (BMV) in an oral topical preparation. This dosage form was made by the addition of PVP and propylene glycol to a chitosan membrane. The membrane was made using the solvent evaporation technique. Chitosan was dissolved in a $2 \%$ acetate acid solution and then mixed continuously for 24 hours. PVP solution and propylene glycol were then added with continuous stirring, and the $\mathrm{pH}$ was adjusted to approximately 5.0 using $1 \mathrm{M}$ $\mathrm{NaOH} .{ }^{95}$ The mixture was poured into Petri dishes and dried in an oven overnight at $50+2^{\circ} \mathrm{C}$. The membranes were immersed in a $5 \%$ tripolyphosphate (TPP) solution with a $\mathrm{pH}$ of about 5.0 and kept at $4{ }^{\circ} \mathrm{C}$ for 1 hour. The membrane was washed several times with water and dried in a desiccator. Betamethasone-17-valerate (BMV) dissolved in $10 \%$ propylene glycol was then added to the membrane. All membranes were evaluated using swelling studies, thickness, XRD, DSC, SEM, mucoadhesive property analysis, and in vitro drug release assays. ${ }^{95}$

The membrane was used to deliver BMV in RAS treatment. The membrane will contact with saliva and swelling in the oral surface. Mucoadhesion occurs by an interaction of positive charge in chitosan with sialic acid in the mucosal surface. ${ }^{55}$

\section{Plates}

Oral ulcer therapy is complex and local treatment options include: decreasing local trauma, anesthesia, preventing infections, fissures, and lesions, decreasing dysbacteriosis, controlling phagocytosis and the regeneration process, surgical intervention of chronic fissures or excrescences, and aiding the restoration process back to normal function. A bioresorbable plate was built to deliver the active compound which has one or several aspects above in RAS treatment. ${ }^{56}$

Bioresorbable preparation is created using a combination of materials with other medicinal substances. This preparation has a wide spectrum of anti-inflammatory actions due to its complex ingredients and, thus, their use is increasing. The bioresorbable plate "Farmadont" is a DDS design based on collagen and herbal extracts. The herbal medicinal plants used in this DDS are aloe, plantain, chamomile, valerian, and arnica, with the addition of digestase, which is a complex of proteolytic enzymes. ${ }^{56}$

When the preparation comes into contact with moist mucosa, the plate begins to absorb the saliva and gradually changes into a gel that adheres to the mucosa. These plates retain the drug on the oral lesions and protect them from salivary environment. The release of both digestase and plant extracts then occurs. Prolongation of action is achieved by the disintegration period of plates in the oral cavity, which is about 45 minutes to 2 hours. The remaining plate does not need to be removed. ${ }^{56}$

\section{Pellicles}

"Pellicle" is the term given to an organic film that naturally covers the surfaces of the teeth. The first research on pellicles was done in 1893, when Alexander Nasmyth observed part of a membrane floating on the surface of the surrounding teeth in an acid reaction. Pellicles are a protein film formed on the enamel surface through selective binding of the glycoproteins in saliva. This film protects the teeth from calcium deposition and is continuously reformed after the tooth is cleaned or following chewing. ${ }^{57}$ This cover is called a persistent dental capsule, while the latter is called a pellicle. ${ }^{57,58}$

Meng et al have used the term "pellicle" to refer to a dental film containing amlexanox in their design of an adhesive pellicle as a vehicle to deliver amlexanox to the oral mucosa. This DDS results in a white lamellar film. The pellicle was formulated using a mucoadhesive polymer of CMC and HPMC in combination with carbomer and magnesium stearate as an excipient. These adhesive pellicles are glutinous and thin, which allows them to adhere to the surface of the oral mucosa more easily than a tablet. ${ }^{96}$

The pellicles containing HPMC and CMC-Na formed a gel. The gel will cover all the surfaces of the mucosa to form a lamellar film. This film protects the ulcer from the oral environment such as saliva, food, etc. The combination of CMC-Na and HPMC will increase the mucoadhesive time of the film at the oral mucosa. ${ }^{57,58}$

\section{Liposomes}

Liposomes have a spherical shape and consist of small vesicles made from long-chain fatty acids, glycolipids, 
sphingolipids, membrane proteins, cholesterols, and nontoxic surfactants. Liposomes display vesicular behavior when dissolved in water: the phospholipids spontaneously create closed structures with internal environments in aqueous solutions via phospholipid bilayer membranes. Liposomes are widely used as a DDS as they can be filled with different types of molecules, such as proteins, small drug molecules, nucleotides, and plasmids. ${ }^{97,98}$

A major problem in the treatment of RAS is penetration of sufficient drug concentrations in the oral mucosa while avoiding systemic drug effects. ${ }^{59,60}$ Other studies comparing drug release between liposomes and creams have found that liposomes retain higher amounts of a drug in both the dermis and epidermis with lower concentrations passing into the subcutaneous tissue and plasma, thus the drug concentration in the urine is very low. ${ }^{60}$

On the other hand, conventional preparations result in higher drug concentrations over shorter periods. Liposomes were developed to increase the concentration of the active ingredients at ulcer sites; incorporating liposomes into the gel provides better treatment. ${ }^{59,60}$

Farshi et al 1996 designed a gelosome, a liposome in a gel, containing dexamethasone sodium phosphate (DSP) to enhance the drug concentration at the oral mucosal. Liposomes as drug carriers are made by mixing the lipids into chloroform until the lipids are completely solubilized. The chloroform is then removed from the solution using a rotary evaporator. When the solvent is removed from the system, a dried thin lipid film remains on the surface of the flask wall. The film is then moisturized using $10 \mathrm{~mL}$ Tris buffer solution at a concentration of $10 \mathrm{mM}$ and $\mathrm{pH}$ of 7.4 at a temperature of $65^{\circ} \mathrm{C}$. The solution is then shaken and vortexed for 1 minute. Next, the liposomes are separated using an ultrasonicator for $30 \mathrm{~min}$ and the mixture is then allowed to stand for 3 hours. The DSP liposomes are separated using ultracentrifugation at 13,500 rpm for 45 minutes, and this ultracentrifugation process is repeated three times. ${ }^{99}$

The next step is the incorporation of the liposomes into the gel, called a "gelosome". Gelosomes are prepared using 1\% Carbopol 940 (Kodak) in distilled water as a gel-forming agent. $1 \% \mathrm{w} / \mathrm{w}$ Carbopol was mixed with water and stirred using a magnetic stirrer. $0.5 \mathrm{~mL} 10 \% \mathrm{NaOH}$ was added to neutralize $1 \mathrm{~g}$ of Carbopol. The Gelosome was made by mixing the gel and liposomes in a 1:1 ratio. ${ }^{99}$

Liposomes display vesicular behavior when dissolved in water: the phospholipids spontaneously create a closed structure with internal environments in aqueous solutions. ${ }^{59,60}$ The drug was entrapped in the liposomes and incorporated in the gel base containing Carbopol. Carbopol was used as a matrix to deliver the liposomes at the oral ulcer. ${ }^{25}$

This preparation was examined in patients resulting in faster ulcer healing times compared to patients treated with Kenacort Orabase Ointment. ${ }^{99}$ Liposomal encapsulation can also be used to deposit drugs in the oral mucosal epithelium. ${ }^{100}$ The gel will adhere to oral mucosa for a prolonged time while the drug is released from the liposome. ${ }^{25,59,60}$

\section{Future Perspective}

RAS ulcer is initiated when a part of the oral cavity feels burning (pre-aesthesia) as the first inflammation process and the mast cells are released. The mast cells stimulate Nuclear Factor Kappa B cells to enter the mitochondria and stimulate the cytokines transcription, molecules adhesion (metalloproteinase/MMP 8 and MMP 1), and proinflammation mediator (Th1: IL-2, IL-12, IFN- $\sqrt{ }$, TNF- $\alpha$; and Th-2: IL-4, IL-5, IL-10, IL-13). TNF- $\alpha$ is the main cytokine that causes acute inflammation and MHC expression. MHC stimulates the cytotoxic cells CD $8+$ resulting in ulcers at the mucosal epithelium. The liberation of Helper T cells CD 4+ proposed the healing process. On the other hand, the release of Nitric Oxygenase (NOX) modulates the presence of ROS as a homeostatic role in normal physiology, proposing a healing process of the ulcer (Figure 2).

The objective of RAS therapy is to decrease the inflammation process of the ulcer. Several drugs and polymers were developed to study their activity in RAS management. The development of DDS for RAS treatment aims to increase the residence times of therapeutics at the sites of ulcers, to release sufficient concentrations of the drug onto the ulcer, and to relieve pain. However, a common barrier to oral mucosa drug delivery is known as "saliva washout", which causes treatments to be ineffective as the drugs are readily rinsed away soon after application. To solve this problem, several studies have been conducted aiming to improve the residence time of drugs on the oral mucosa. Almost all the studies modified the DDS in oral mucosa to increase the healing effect of RAS preparation through the combination or modification of polymer as a vehicle. The mucoadhesive preparation was applicable for both natural and synthetic drugs for RAS therapy, resulting in a faster healing time and decrease inflammation in RAS 
ulcers. The preparation should be comfortable and easy in application.

\section{Conclusion}

Various preparation forms for RAS treatment have been developed containing both active substances and excipients. The excipients used in RAS preparations play multiple roles in either delivering the drug to the target site or providing a healing effect based on their adhesiveness and ability to cover the oral mucosal. The objective of this review is to study the development of the various preparation forms used as RAS treatments from 1965 until February 2020. There are several publications regarding RAS, but there are few articles discussing the several dosage forms for RAS. Most of the published articles scrutinize the clinical study of some DDS for RAS without discussion about the formulation, evaluation and Dof their preparation. The most favorable DDS for RAS preparation is semi-solid forms, which include 5 types of DDS. Meanwhile, solid forms have 4 types of DDS and liquid forms has 4 types. Liquid, semi-solid, and solid forms have been developed into new DDS, such as adhesive alginates, Dentifrice, OraDisc, membranes, bioresorbable plates, pellicles, and gelosomes. These preparations are designed to improve the drug delivery and drug activity for the treatment of RAS ulcers, but almost all the DDS are topical preparations that use various types of mucoadhesive polymers to increase both drug residence times and the relief of pain associated with RAS ulcers.

\section{Abbreviations}

RAS, Recurrent Aphthous Stomatitis; DDS, Drug Delivery System; TNF- $\alpha$, Tumor Necrosis Factor alpha (TNF- $\alpha$ ); EDAC, 1- ethyl-3- (3-dimethylamino propyl) carbodiimide hydrochloride; LA, Listerine Antiseptic; MHC, Major Histocompatibility Complex; IL, interleukin; ROS, Reactive Oxygen Species; PDL, Pudilan Xiaoyan Oral Liquid; PKT, Pudilan Keyaning Toothpaste; MC, methylcellulose; CMC, Carboxymethylcellulose; HPEC, Hydroxypropylethylcellulose; HPMC, Hydroxypropylmethylcellulose; SCMC, Sodium carboxymethylcellulose; HA, Hyaluronic Acid; PEG, Polyethylene glycol; HIV, Human Immunodeficiency Virus; SLNs, Solid Lipid Nanoparticles; CsA, Cyclosporine A; iNOS, inducible Nitric Oxide Synthase; bGF, basic Fibroblast Growth Factor; PE, polyethylene; HDPE, high-density polyethylene; LDPE, low-density polyethylene; MDFs, Mouth Dissolved Films;
DSP, Dexamethasone Sodium Phosphate; PEO, Polyethylenoxyde; TPP, tripolyphosphate; BMV, Betamethasone-17-valerate; PVP, polyvinylpyrrolidone.

\section{Acknowledgments}

We would like to thank the Minister of Research and Higher Education, Republic of Indonesia, for funding this study.

\section{Funding}

This research was funded by the College Superior Applied Research (Penelitian Terapan Unggulan Perguruan Tinggi) and Doctoral Dissertation Research Grants, Ministry of Culture and Education, Republic of Indonesia, grant number 1207/UN6.3.1/PT.00/2021.

\section{Disclosure}

The authors declare no conflicts of interest for this work.

\section{References}

1. Jurge S, Kuffer R, Scully C, Porter SR. Number VI Recurrent aphthous stomatitis. Oral Dis. 2006;12(1):1-21. doi:10.1111/ j.1601-0825.2005.01143.x

2. Cui RZ, Bruce AJ, Rogers RS. Recurrent aphthous stomatitis. Clin Dermatol. 2016;34(4):475-481. doi:10.1016/j. clindermatol.2016.02.020

3. Tiwari G, Tiwari R, Sriwastawa B, et al. Drug delivery systems: an updated review. Int $J$ Pharm Investig. 2012;2(1):2-11. doi:10.4103/2230-973X.96920

4. Oliveira MJ, Coimbra F, Mesquita P, Carvalho J, Pereira-Lopes O. Characterization of recurrent aphthous stomatitis in a young population. Rev Port Estomatol Med Dent Cir Maxilofac. 2018;59 (1):10-17. doi:10.24873/j.rpemd.2018.06.222

5. Boddupalli BM, Mohammed ZN, Nath RA. Mucoadhesive drug delivery system: an overview. J Adv Pharm Technol Res. 2010;1 (4):381-387. doi:10.4103/0110-5558.76436

6. Shaikh R, Raghu T, Singh R, Garland MJ, David A, Donnelly RF. Mucoadhesive drug delivery systems. J Pharm Bioallied Sci. 2011;3(1):89-100. doi:10.4103/0975-7406.76478

7. Taylor CG, Dc U, Alexander RE. Federal dental services. 1965.

8. Meiller TF, Kutcher MJ, Overholser CD, Niehaus C, DePaola LG, Siegel MA. Effect of an antimicrobial mouthrinse on recurrent aphthous ulcerations. Oral Surg Oral Med Oral Pathol. 1991;72 (4):425-429. doi:10.1016/0030-4220(91)90553-O

9. Laffleur F, Küppers P. Adhesive alginate for buccal delivery in aphthous stomatitis. Carbohydr Res. 2019;477:51-57. doi:10.1016/j.carres.2019.03.009

10. Wathoni N, Yuniarsih N, Cahyanto A, Muhctaridi M. $\alpha$-mangostin hydrogel film based chitosan-alginate for recurrent aphthous stomatitis. Appl Sci. 2019;9(23):5235. doi:10.3390/app9235235

11. Compilato D, Carroccio A, Calvino F, Di Fede G, Campisi G. Haematological deficiencies in patients with recurrent aphthosis. $J$ Eur Acad Dermatology Venereol. 2010. doi:10.1111/j.14683083.2009.03482.x

12. Natah SS, Konttinen YT, Enattah NS, Ashammakhi N, Sharkey KA, Häyrinen-Immonen R. Recurrent aphthous ulcers today: a review of the growing knowledge. Int J Oral Maxillofac Surg. 2004;33(2):221-234. doi:10.1054/ijom.2002.0446 
13. Bazrafshani MR, Hajeer AH, Ollier WER, Thornhill MH. IL-1B and IL-6 gene polymorphisms encode significant risk for the development of recurrent aphthous stomatitis (RAS). Genes Immun. 2002;3(5):302-305. doi:10.1038/sj.gene.6363882

14. Bhaskar SN, Jacoway JR, Margetis PM, et al. Oral tissue response to chemical adhesives (cyanoacrylates). Oral Surg Oral Med Oral Pathol. 1966;22(3):394-404. doi:10.1016/0030-4220(66)90314-8

15. Addy M, Hunter L. The effects of a $0.2 \%$ chlorhexidine gluconate mouthrinse on plaque, toothstaining and candida in aphthous ulcer patients: a double-blind placebo-controlled cross-over study. J Clin Periodontol. 1987;14(5):267-273. doi:10.1111/ j.1600-051X.1987.tb01531.x

16. Nguyen S, Hiorth M. Advanced drug delivery systems for local treatment of the oral cavity. Ther Deliv. 2015;6(5):197-210. doi: $10.4155 /$ tde. 15.5

17. Tian G, Li C, Zhai Y, et al. GC-MS based metabolomic profiling of lung tissue couple with network pharmacology revealed the possible protection mechanism of Pudilan Xiaoyan Oral Liquid in LPS-induced lung injury of mice. Biomed Pharmacother. 2020;124:109833. doi:10.1016/j.biopha.2020.109833

18. Teixeira F, Mosqueda-Taylor A, Montano S, Dominguez-Soto L. Treatment of recurrent oral ulcers with mometasone furoate lotion. Postgr Med J. 1999;75(887):574. doi:10.1136/ pgmj.75.887.574a

19. Jones D. Pharmaceutics-Dosage Form and Design. Pharmaceutical press; 2008

20. Scott JD, Bender B. Treatment of recurrent aphthous ulcers with a corticosteroid inhaler in patients with HIV disease. AIDS Patient Care STDS. 1996;10(3):152-153. doi:10.1089/apc.1996.10.152

21. Kapoor P, Sachdeva S, Sachdeva S. Topical hyaluronic acid in the management of oral ulcers. Indian J Dermatol. 2011;6(3):300302. doi:10.4103/0019-5154.82485

22. Lee JH, Jung JY, Bang D. The efficacy of topical $0.2 \%$ hyaluronic acid gel on recurrent oral ulcers: comparison between recurrent aphthous ulcers and the oral ulcers of Behçet's disease. $J$ Eur Acad Dermatology Venereol. 2008;22(5):590-595. doi:10.1111/ j.1468-3083.2007.02564.x

23. Koray M, Ofluoglu D, Senemtasi A, et al. The efficacy of hyaluronic acid gel in pain control of recurrent aphthous stomatitis. Int J Dent Oral Sci. 2016;3:273-275. doi:10.19070/2377-80751600055

24. Nolan A, Baillie C, Badminton J, Rudralingham M, Seymour RA. The efficacy of topical hyaluronic acid in the management of recurrent aphthous ulceration. J Oral Pathol Med. 2006;35 (8):461-465. doi:10.1111/j.1600-0714.2006.00433.x

25. Singla AK, Chawla M, Singh A. Potential applications of carbomer in oral mucoadhesive controlled drug delivery system: a review. Drug Dev Ind Pharm. 2000;26(9):913-924. doi:10.1081/ DDC-100101318

26. Ambrosio L, Demitri C, Sannino A. Superabsorbent cellulosebased hydrogels for biomedical applications. Biomedical Hydrogels. 2011;25-50. doi:10.1533/9780857091383.1.25

27. Fini A, Bergamante V, Ceschel GC. Mucoadhesive gels designed for the controlled release of chlorhexidine in the oral cavity. Pharmaceutics. 2011;3:665-679. doi:10.3390/ pharmaceutics3040665

28. Mansour G, Ouda S, Shaker A, et al. Clinical efficacy of new aloe vera- and myrrh-based oral mucoadhesive gels in the management of minor recurrent aphthous stomatitis: a randomized, doubleblind, vehicle-controlled study. J Oral Pathol Med. 2014. doi:10.1111/jop. 12130

29. Haghpanah P, Moghadamnia AA, Zarghami A, Motallebnejad M. Muco-bioadhesive containing ginger officinale extract in the management of recurrent aphthous stomatitis: a randomized clinical study. Casp J Intern Med. 2015;6(1):3-8.
30. Jiang XW, Zhang Y, Zhang H, Lu K, Yang SK, Sun GL. Doubleblind, randomized, controlled clinical trial of the effects of diosmectite and basic fibroblast growth factor paste on the treatment of minor recurrent aphthous stomatitis. Oral Surg Oral Med Oral Pathol Oral Radiol. 2013;116(5):570-575. doi:10.1016/j. oooo.2013.07.003

31. Bhat S, Sujatha D. A clinical evaluation of $5 \%$ amlexanox oral paste in the treatment of minor recurrent aphthous ulcers and comparison with the placebo paste: a randomized, vehicle controlled, parallel, single center clinical trial. Indian J Dent Res. 2013;24(5):593. doi:10.4103/0970-9290.123382

32. Khandwala A, Van Inwegen RG, Alfano MC. $5 \%$ amlexanox oral paste, a new treatment for recurrent minor aphthous ulcers: I. Clinical demonstration of acceleration of healing and resolution of pain. Oral Surg Oral Med Oral Pathol Oral Radiol Endod. 1997;83(2):222-230. doi:10.1016/S1079-2104(97)90009-3

33. Yang Y, Zhang T, Dong Z, Wu Y, Hong X, Hu T. Short-term efficacy of pudilan keyanning toothpaste in treatment of minor recurrent aphthous ulcers. Evidence-Based Complement Altern Med. 2016;2016:1-7. doi:10.1155/2016/9125327

34. Ali HS, Abdul Rasool BK. Propolis buccal paste in treatment of aphthous ulceration: formulation and clinical evaluation. Asian $J$ Pharm Clin Res. 2011;4(4):29-33.

35. Lozada-Nur F, Huang MZ. Open preliminary clinical trial of clobetasol propionate ointment in adhesive paste for treatment of chronic oral vesiculoerosive diseases. Oral Surg Oral Med Oral Pathol. 1991;71(3):283-287. doi:10.1016/0030-4220(91) 90300-2

36. Raeesi V, Arbabi-Kalati F, Akbari N, Hamishehkar H. Comparison effectiveness of the bioadhesive paste containing licorice $5 \%$ with bioadhesive paste without drug in the management of recurrent aphthous stomatitis. Acta Medica Mediterr. 2015;31(7):1331-1335.

37. Hamishehkar H, Nokhodchi A, Ghanbarzadeh S, Kouhsoltani M. Triamcinolone acetonide oromucoadhesive paste for treatment of aphthous stomatitis. Adv Pharm Bull. 2015;5(2):277-282. doi:10.15171/apb.2015.038

38. Rabinovich IM, Banchenko GV, Rabinovich OF, et al. A clinical study of solcoseryl dental adhesive paste and mundisal gel in the treatment of chronic recurrent aphthous and herpetic stomatitides. Stomatol. 1999;78(6):20-22.

39. Ghosal K, Chakrabarty S, Nanda A. Hydroxypropyl methylcellulose in drug delivery. Der Pharmacia Sinica. 2011;2(2):152168.

40. Sakly A, De Wever B, Jutla B, Satia M, Bogaert JP. The safety and efficacy of AphtoFix ${ }^{\circledR}$ mouth ulcer cream in the management of recurrent aphthous stomatitis. BMC Oral Health. 2016;16 (1):1-7. doi:10.1186/s12903-016-0177-0

41. Guo Q, Yang J, Yu M. Observing the effect of traditional Chinese medicine Kouchuang Xiaotong powder on patients with recurrent aphthus ulcer. Pak J Pharm Sci. 2018;31(4):1687-1690.

42. Gao MS, Liu S, Wang AW. Preparation and clinical observation of Koukuining granules in 50 patients with recurrent aphthous ulcer. Shanghai Kou Qiang Yi Xue. 2016;25:579-582.

43. Liu J, Zeng X, Chen Q, et al. An evaluation on the efficacy and safety of amlexanox oral adhesive tablets in the treatment of recurrent minor aphthous ulceration in a Chinese cohort: a randomized, double-blind, vehicle-controlled, unparallel multicenter clinical trial. Oral Surg Oral Med Oral Pathol Oral Radiol Endod. 2006;102(4):475-481. doi:10.1016/j.tripleo.2005.12.014

44. Deen K, Curchin C, Wu J. Successful treatment of recurrent aphthous ulcers with nicotine lozenges in a lifelong non-smoker. Australas J Dermatol. 2015;56(2):143-144. doi:10.1111/ ajd.12261 
45. Zhou Y, Chen Q, Meng W, et al. Evaluation of penicillin G potassium troches in the treatment of minor recurrent aphthous ulceration in a Chinese cohort: a randomized, double-blinded, placebo and no-treatment-controlled, multicenter clinical trial. Oral Surg Oral Med Oral Pathol Oral Radiol Endod. 2010;109 (4):561-566. doi:10.1016/j.tripleo.2009.11.006

46. Sharma D, Sharma A, Garg R. Preparation, physicochemical evaluation and characterization of mucoadhesive buccal gels impregnated with benzydamine hydrochloride for the effective treatment of aphthous stomatitis: effect of different grades of HPMC polymer on in vitro and ex vivo perf. Drug Deliv Lett. 2019;9(4):341-357. doi:10.2174/2210303109666190529123029

47. Colley HE, Said Z, Santocildes-Romero ME, et al. Pre-clinical evaluation of novel mucoadhesive bilayer patches for local delivery of clobetasol-17-propionate to the oral mucosa. Biomaterials. 2018;178:134-146. doi:10.1016/j.biomaterials.2018.06.009

48. Moghadamnia AA, Motallebnejad M, Khanian M. The efficacy of the bioadhesive patches containing licorice extract in the management of recurrent aphthous stomatitis. Phyther Res. 2009;23 (2):246-250. doi:10.1002/ptr.2601

49. Kutcher MJ, Ludlow JB, Samuelson AD, Campbell T, Pusek SN. Evaluation of a bioadhesive device for the management of aphthous ulcers. J Am Dent Assoc. 2001;132(3):368-376. doi:10.14219/jada.archive.2001.0180

50. Scully C, Gorsky M, Lozada-Nur F. The diagnosis and management of recurrent aphthous stomatitis: a consensus approach. $J$ Am Dent Assoc. 2003;134(2):200-207. doi:10.14219/jada. archive.2003.0134

51. Fujisawa Y, Sakamoto M, Matsushita M, Fujita T, Nishioka K. Glycyrrhizin inhibits the lytic pathway of complement - possible mechanism of its anti-inflammatory effect on liver cells in viral hepatitis. Microbiol Immunol. 2000;44(9):799-804. doi:10.1111/ j.1348-0421.2000.tb02566.x

52. Hashemi M, Ramezani V, Seyedabadi M, et al. Formulation and optimization of oral mucoadhesive patches of Myrtus communis by box behnken design. Adv Pharm Bull. 2017;7(3):441-450. doi:10.15171/apb.2017.053

53. Henricsson V, Axéll T. Treatment of recurrent aphthous ulcers with aureomycin ${ }^{\circledR}$ mouth rinse or zendium ${ }^{\circledR}$ dentifrice. Acta Odontol Scand. 1985;43(1):47-52. doi:10.3109/00016358509064139

54. Murray B, Biagioni PA, Lamey PJ. The efficacy of amelxanox $\mathrm{OraDisc}^{\mathrm{TM}}$ on the prevention of recurrent minor aphthous ulceration. J Oral Pathol Med. 2006;35(2):117-122. doi:10.1111/ j.1600-0714.2006.00379.x

55. Mohammed MA, Syeda JTM, Wasan KM, Wasan EK. An overview of chitosan nanoparticles and its application in non-parenteral drug delivery. Pharmaceutics. 2017;9(4):53. doi:10.3390/ pharmaceutics 9040053

56. Vladimirovich TA, Vladimirovich SA, Vladimirovich DG, Valerevich IA, Dmitrievna TM. Use of bioresorbable plates on the basis of collagen and digestase for treatment of diseases of oral mucosa (review of clinical cases). Int $J$ Green Pharm. 2018;12(1):S290-S296.

57. Lendenmann U, Grogan J, Oppenheim FG. Saliva and dental pellicle - a review. Adv Dent Res. 2000;14:22-28. doi:10.1177/ 08959374000140010301

58. Nasmyth A. On the structure, physiology, and pathology, of the persistent capsular investments and pulp of the tooth. Med Chir Trans. 1839;22:310-328. doi:10.1177/095952873902200123

59. Sveinsson SJ, Peter Holbrook W. Oral mucosal adhesive ointment containing liposomal corticosteroid. Int J Pharm. 1993;95(13):105-109. doi:10.1016/0378-5173(93)90396-W

60. Foong WC, Harsanyi BB, Mezei M. Biodisposition and histological evaluation of topically applied retinoic acid in liposomal, cream and gel dosage forms. In: Phospholipids. Boston, MA: Springer; 1990:279-282. doi:10.1007/978-1-4757-1364-0_25
61. Parashar A. Mouthwashes and their use in different oral conditions. Sch J Dent Sci J Dent Sci. 2015;2(2B):186-191.

62. Vranić E, Lacević A, Mehmedagić A, Uzunović A. Formulation ingredients for toothpastes and mouthwashes. Bosn J Basic Med Sci. 2004;4(4):51-58. doi:10.17305/bjbms.2004.3362

63. Hoseinpour H, Peel SAF, Rakhshandeh H, et al. Evaluation of Rosa damascena mouthwash in the treatment of recurrent aphthous stomatitis: a randomized, double-blinded, placebo-controlled clinical trial. Quintessence Int. 2011;42(6):483-491.

64. Mansoori P, Ghavami R, Shafiei A. Clinical evaluation of Zataria Multiflora essential oil mouthwash in the management of recurrent Aphthous Stomatitis. DARU J Pharm Sci. 2002;10(2):74-77.

65. Sharquie KE, Al-Tammimy SM, Al-Mashhadani S, Hayani RK, Al-Nuaimy AA. Lactic acid 5 percent mouthwash is an effective mode of therapy in treatment of recurrent aphthous ulcerations. Dermatol Online J. 2006;12(7). doi:10.5070/D3800902VZ

66. Gorsky M, Epstein JB, Rabenstein S, Elishoov H, Yarom N. Topical minocycline and tetracycline rinses in treatment of recurrent aphthous stomatitis: a randomized cross-over study. Dermatol Online J. 2007;13(2):1.

67. Jin Y, Lin X, Song L, et al. The effect of pudilan anti-inflammatory oral liquid on the treatment of mild recurrent aphthous ulcers. Evid-Based Complement Altern Med. 2017;2017:1-6. doi:10.1155/2017/6250892

68. Deng W, Xu Y, Kong Q, et al. Therapeutic efficacy of Pudilan Xiaoyan Oral Liquid (PDL) for COVID-19 in vitro and in vivo. Signal Transduct Target Ther. 2020;5:1-3. doi:10.1038/s41392020-0176-0

69. Kawano Y, Imamura A, Nakamura T, Akaishi M, Satoh M, Hanawa T. Development and characterization of oral spray for stomatitis containing irsogladine maleate. Chem Pharm Bull. 2016;64(12):1659-1665. doi:10.1248/cpb.c16-00217

70. Liguori V, Guillemin C, Pesce GF, Mirimanoff RO, Bernier J. Double-blind, randomized clinical study comparing hyaluronic acid cream to placebo in patients treated with radiotherapy. Radiother Oncol. 1997;42(2):155-161. doi:10.1016/S0167-8140 (96)01882-8

71. Matsuno H, Yudoh K, Kondo M, Goto M, Kimura T. Biochemical effect of intra-articular injections of high molecular weight hyaluronate in rheumatoid arthritis patients. Inflamm Res. 1999;48 (3):154-159. doi:10.1007/s000110050439

72. Weindl G, Schaller M, Schäfer-Korting M, Korting HC. Hyaluronic acid in the treatment and prevention of skin diseases: molecular biological, pharmaceutical and clinical aspects. Skin Pharmacol Physiol. 2004;17(5):207-213. doi:10.1159/000080213

73. Dalessandri D, Zotti F, Laffranchi L, et al. Treatment of recurrent aphthous stomatitis (RAS; aphthae; canker sores) with a barrier forming mouth rinse or topical gel formulation containing hyaluronic acid: a retrospective clinical study. BMC Oral Health. 2019;19(1):153. doi:10.1186/s12903-019-0850-1

74. Aslani A, Zolfaghari B, Davoodvandi F. Design, formulation and evaluation of an oral gel from Punica granatum flower extract for the treatment of recurrent aphthous stomatitis. Adv Pharm Bull. 2016;6(3):391-398. doi:10.15171/apb.2016.051

75. Burgess JA, Johnson BD, Sommers E. Pharmacological management of recurrent oral mucosal ulceration. Drugs. 1990;39(1):5465. doi:10.2165/00003495-199039010-00005

76. Salamat-Miller N, Chittchang M, Johnston TP. The use of mucoadhesive polymers in buccal drug delivery. Adv Drug Deliv Rev. 2005;57(11):1666-1691. doi:10.1016/j.addr.20 05.07.003

77. Sudhakar Y, Kuotsu K, Bandyopadhyay AK. Buccal bioadhesive drug delivery - a promising option for orally less efficient drugs. $J$ Control Release. 2006;114(1):15-40. doi:10.1016/j. jconrel.2006.04.012 
78. Kaffashi B, Zandieh A. Drug release study of systems containing the tragacanth and collagen composite: release characterization and viscoelastic measurements. Macromol Symp. 2006;239:120 129. doi: $10.1002 /$ masy. 200650718

79. Kia SJ, Mansourian A, Basirat M, Akhavan M, MohtashamAmiri Z, Moosavi MS. New concentration of curcumin orabase in recurrent aphthous stomatitis: a randomized, controlled clinical trial. J Herb Med. 2020;22:100336. doi:10.1016/j.hermed.20 20.100336

80. Stabenfeldt SE, García AJ, LaPlaca MC. Thermoreversible laminin-functionalized hydrogel for neural tissue engineering. $J$ Biomed Mater Res. 2006;77(4(Part A)):718-725. doi:10.1002/ jbm.a.30638

81. Liu L, Fishman ML, Hicks KB. Pectin in controlled drug delivery - a review Pectin in controlled drug delivery - a review. Cellulose. 2007;14:15-24. doi:10.1007/s10570-006-9095-7

82. Inoue H, Mori T, Shibata S, Koshihara Y. Modulation by glycyrrhetinic acid derivatives of TPA-induced mouse ear oedema. $\mathrm{Br} J$ Pharmacol. 1989;96(1):204-210. doi:10.1111/j.1476-5381.1989. tb11801.x

83. Mahdi AB, Coulter WA, Woolfson AD, Lamey PJ. Efficacy of bioadhesive patches in the treatment of recurrent aphthous stomatitis. J Oral Pathol Med. 1996;25(8):416-419. doi:10.1111/ j.1600-0714.1996.tb00289.x

84. Shapiro S, Olson DL, Chellemi SJ. The association between smoking and aphthous ulcers. Oral Surg Oral Med Oral Pathol. 1970;30(5):624-630. doi:10.1016/0030-4220(70)90384-1

85. Bittoun R. Recurrent aphthous ulcers and nicotine. Med J Aust. 1991;154(7):471-472. doi:10.5694/j.1326-5377.1991.tb121180.x

86. Khairnar A, Jain P, Baviskar D, Jain D. Development of mucoadhesive buccal patch containing aceclofenac: in vitro evaluations. Int J PharmTech Res. 2009;1:978-981.

87. Martins A, Reis RL, Neves NM. Electrospinning: processing technique for tissue engineering scaffolding. Int Mater Rev. 2008;53(5):257-275. doi:10.1179/174328008X353547

88. Martin MD, Sherman J, Peter van der Ven JB. A controlled trial of a dissolving oral patch concerning glycyrrhiza (licorice) herbal extract for the treatment of aphthous ulcers. Gen Dent. 2008;56 (2):206-210.

89. Martins ICF, Raposo NRB, Mockdeci HR, et al. Delivering resveratrol on the buccal mucosa using mucoadhesive tablets: a potential treatment strategy for inflammatory oral lesions. Curr Drug Deliv. 2018;15:254-259. doi:10.2174/15672018146661 70726102558
90. Subramanyam RV. Occurrence of recurrent aphthous stomatitis only on lining mucosa and its relationship to smoking - a possible hypothesis. Med Hypotheses. 2011;77(2):185-187. doi:10.1016/j. mehy.2011.04.006

91. M Farid R, Ming Wen M. Promote recurrent aphthous ulcer healing with low dose prednisolone bilayer mucoadhesive buccal film. Curr Drug Deliv. 2016. doi:10.2174/156720181366 6160316122548

92. Stagi S, Bertini F, Rigante D, Falcini F. Vitamin D levels and effects of vitamin D replacement in children with periodic fever, aphthous stomatitis, pharyngitis, and cervical adenitis (PFAPA) syndrome. Int J Pediatr Otorhinolaryngol. 2014;78:964-968. doi:10.1016/j.ijporl.2014.03.026

93. Pharm RB, Pharm GA, Yazdanian E, et al. Formulation and evaluation of triamcinolone acetonide mucoadhesive film as treatment of aphthous stomatitis and oral inflammatory diseases. $J$ Isfahan Med Sch. 2013;30:2419-2431.

94. Humphrey SP, Williamson RT. A review of saliva normal composition, flow, and function. J Prosthet Dent. 2001;85(2):162169. doi: $10.1067 / \mathrm{mpr} .2001 .113778$

95. Sizílio RH, Galvão JG, Trindade GGG, et al. Chitosan/pvp-based mucoadhesive membranes as a promising delivery system of betamethasone-17-valerate for aphthous stomatitis. Carbohydr Polym. 2018;190:339-345. doi:10.1016/j.carbpol.2018.02.079

96. Meng W, Dong Y, Liu J, et al. A clinical evaluation of amlexanox oral adhesive pellicles in the treatment of recurrent aphthous stomatitis and comparison with amlexanox oral tablets: a randomized, placebo controlled, blinded, multicenter clinical trial. Trials. 2009;10:1-7. doi:10.1186/1745-6215-10-30

97. Franz-Montan M, de Araújo DR, de Morais Ribeiro LN, de Melo NFS, de Paula E. Nanostructured systems for transbuccal drug delivery. Nanostructures Oral Med. 2017;87-121. doi:10.1016/ B978-0-323-47720-8.00005-5

98. Ravichandiran V, Masilamani K, Senthilnathan B. Liposome - a versatile drug delivery system. Drugs. 2011;2(1):19-30.

99. Farshi FS, Özer AY, Tavassoli S, Sungur A, Hincal AA. A clinical trial: in vivo studies on dexamethasone sodium phosphate liposomes in the treatment of human Aphthous stomatitis. J Liposome Res. 1996;6(4):699-712. doi:10.3109/08982109609039922

100. Harsanyi BB, Hilchie JC, Mezei M. Liposomes as drug carriers for oral ulcers. J Dent Res. 1986;65(9):1133-1141. doi:10.1177/ 00220345860650090501

\section{Publish your work in this journal}

Drug Design, Development and Therapy is an international, peerreviewed open-access journal that spans the spectrum of drug design and development through to clinical applications. Clinical outcomes, patient safety, and programs for the development and effective, safe, and sustained use of medicines are a feature of the journal, which has also been accepted for indexing on PubMed Central. The manuscript management system is completely online and includes a very quick and fair peer-review system, which is all easy to use. Visit http://www. dovepress.com/testimonials.php to read real quotes from published authors. 